\title{
Influence of Ni-P Coated SiC and Laser Scan Speed on the Microstructure and Mechanical Properties of IN625 Metal Matrix Composites
}

\author{
N. H. Sateesh ${ }^{1}$ • G. C. Mohan Kumar ${ }^{1}$. \\ Prasad Krishna ${ }^{1}$
}

Accepted: 7 July 2015 / Published online: 10 September 2015

(C) Springer New York 2015

\begin{abstract}
Nickel based Inconel-625 (IN625) metal matrix composites (MMCs) were prepared using pre-heated nickel phosphide (Ni-P) coated silicon carbide (SiC) reinforcement particles by Direct Metal Laser Sintering (DMLS) additive manufacturing process under inert nitrogen atmosphere to obtain interface influences on MMCs. The distribution of $\mathrm{SiC}$ particles and microstructures were characterized using optical and scanning electron micrographs, and the mechanical behaviours were thoroughly examined. The results clearly reveal that the interface integrity between the $\mathrm{SiC}$ particles and the IN625 matrix, the mixed powders flowability, the SiC ceramic particles and laser beam interaction, and the hardness, and tensile characteristics of the DMLS processed MMCs were improved effectively by the use of Ni-P coated $\mathrm{SiC}$ particles.
\end{abstract}

Keywords Metalmatrix composite $\cdot$ IN625 $\cdot$ Ni-P coated SiC $\cdot$ Directmetal laser sintering

\section{Introduction}

Metal Matrix Composites (MMCs) have been explored for wider applications in the field of engineering for the past three decades. The unique properties such as higher stiffness and lower density which are not possible by conventional materials can be achieved through MMCs. It is hardly difficult to find a material which is stiff as well as having lower density. This type of combined yields can be achieved particularly through the use of ceramic reinforcements in MMCs [16]. The industrial operations such as drawing, rolling, punching and stamping use Ni based MMCs [17]. Ni based materials are high temperature materials with superior mechanical properties and finds

N. H. Sateesh

sateeshnijagal@gmail.com

1 Department of Mechanical Engineering, National Institute of Technology Karnataka (NITK),

Srinivasnagar, Surathkal 575025 Karnataka, India 
application in marine, aeronautic, nuclear, chemical, and petrochemical industries $[12,15]$. IN625 is one such Ni based super-alloy used in such industries because of its attractive properties such as good resistance to oxidation and corrosion, resistance to strain age cracking, and outstanding creep resistance at high temperatures. Silicon Carbide $(\mathrm{SiC})$ which is a ceramic compound of silicon and carbon was chosen as reinforcement for preparing IN625 MMCs. The high hardness and wear resistance, low density, high mechanical strength, ability to retain strength at high temperature, resistance to thermal crack, low thermal expansion and excellent chemical resistance has made $\mathrm{SiC}$ as a choice of reinforcement in IN625 matrix [9]. The addition of these ceramic particulates will improve the limited wear and hardness properties of nickel based IN625. In addition to its low cost and better mechanical properties, the selection of $\mathrm{SiC}$ as the ceramic reinforcement was based on its wide availability in particulate form and stability under laser. The increase in SiC content results in decrease of coefficient of thermal expansion (CTE) and also the additive nature of the laser process avoids the problems associated with machining of the ceramic phase. Materials with CTE from 4 to $7 \times 10^{-6} / \mathrm{K}$ perform better with respect to thermal management [10]. Therefore the IN625 with marginally high CTE can be mixed with SiC with low CTE to form MMCs. The decomposition of $\mathrm{SiC}$ results in precipitation during laser melting. $\mathrm{SiC}$ absorbs larger part of the incident laser energy and at the same time larger part of the incident laser beam is reflected by the metal surface. The hardness of the surface is also found to be increased because of the extensive precipitation of the carbides and also due to laser treatment [19].

The mechanical properties of MMCs depend upon the stability and strength of the region of interface between matrix and particles of reinforcement. The wettability between the reinforcement and the matrix has to be improved by avoiding the formation of unwanted reactions at the interface. One approach that has been adopted so far is to besmear particles of reinforcement, which results in modification of interfacial structure and promotion of wettability [17]. The challenge of improvement in the wettability can be achieved by encapsulating the reinforcement ceramic particle by metal coating. The coating on the ceramic effectively avoids the formation of cracks or voids at the interface of metal/ceramic and ceramic particles clustering in laser processed MMCs.

The present work aims at use of Ni-P coated SiC as the ceramic phase in IN625 for forming the MMCs. Microstructures were studied using optical and scanning electron micrographs. Mechanical properties such as hardness, tensile strength, yield strength, elongation were thoroughly investigated. Influence of laser scan speed and different weight percentage of Ni-P coated $\mathrm{SiC}$ particles on properties of the laser deposited material were analyzed.

\section{Experimental Methods}

IN625 and SiC (NiP-coated) in particulate form were chosen as matrix and reinforcement material. The chemical composition of IN625 is shown in Table 1. The evaluation for morphology of IN625 and SiC (NiP-coated) particles and the elemental analysis were done using scanning electron microscope of make: Carl Zeiss, and model: Neon 40 crossbeam. Particle size analysis was carried out on both IN625 and SiC (NiP- 
Table 1 Chemical composition (in wt. \%) of IN625 (powder alloy corporation, USA)

\begin{tabular}{lllllllllllll}
\hline $\mathrm{Ni}$ & $\mathrm{C}$ & $\mathrm{Fe}$ & $\mathrm{Mn}$ & $\mathrm{Si}$ & $\mathrm{Cr}$ & $\mathrm{Mo}$ & $\mathrm{Nb}+\mathrm{Ta}$ & $\mathrm{Al}$ & $\mathrm{P}$ & $\mathrm{S}$ & $\mathrm{Co}$ & $\mathrm{Ti}$ \\
\hline 58.0 & 0.10 & 5.0 & 0.50 & 0.50 & $20.0-23.0$ & $8.0-10.0$ & $3.15-4.15$ & 0.40 & 0.015 & 0.015 & 1.0 & 0.40 \\
& $\max$ & $\max$ & $\max$ & $\max$ & & & & $\max$ & $\max$ & $\max$ & $\max$ & $\max$ \\
\hline
\end{tabular}

coated) particles using laser based particle size analyser of make: HRLD, USA and model: 8000A. A known quantity of $20 \mathrm{mg}$ of IN625 particles were mixed with an ultra clean hydraulic oil of NAS class ' 0 ' cleanliness. The particle-oil mixture was thoroughly mixed with mechanical agitator and then passed through particle size counter. The same procedure was adopted for particle size analysis of $\mathrm{SiC}$ particles.

The SiC particles were now coated with Nickel-Phosphide (Ni-P) for proper wetting and bonding with the matrix material. The coating also helps in better flowability of the reinforcement particles during blending and laser processing. The coated particles will have more effective particle feeding capacity compared to uncoated particles because there will be an increase in SiC particle mass in the sense the density will be improved, with smooth surface and better spherical morphology. The processing of SiC particles using laser beam is very difficult, when compared to metals because of their high melting point and poor thermal shock character. When such particles are coated with the Ni-P, the thermal shock characters are reduced during their exposure to laser beam and also there will be reduction in porosity [17]. Ni-P coating was carried out on SiC particles by electroless coating process [7]. The coated $\mathrm{SiC}$ particles were heat treated at $400{ }^{\circ} \mathrm{C}$ to convert coated nickel particles from amorphous to stable crystalline state with $\mathrm{Ni}$ and $\mathrm{Ni}_{3}$ phases which helps in proper bonding with the IN625 matrix during laser processing.

The homogeneity of particulate-mixture of IN625 and SiC (NiP-coated) decides the quality of IN625 MMCs. So, the blending of particles plays a key role in processing of composites using laser. Blending was carried out in a double cone blender of make: Hindustan Engineering company, Calcutta and model: DCB-LAB. It is shown in the Fig. 1. The blending time of $5 \mathrm{~min}$ and blending speed of $48 \mathrm{rpm}$ was used to prepare 250 gram of IN625 and 1, 3, 5 wt. \% SiC(NiP-coated) particulate mixture [14].
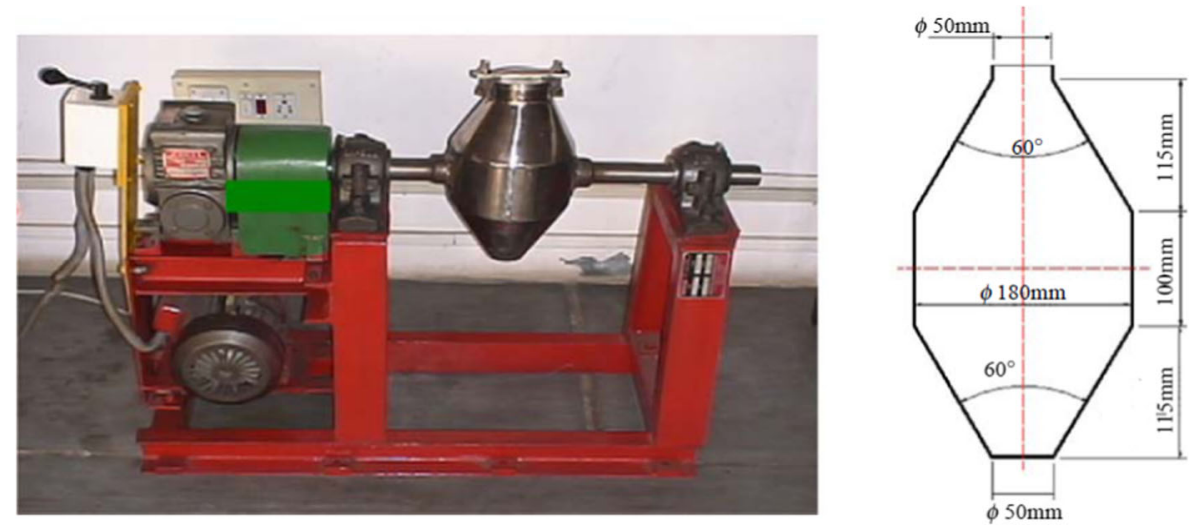

Fig. 1 Double cone blender with schematic diagram of conical container 
Stainless steel rectangular bar of higher hardness is used as the substrate material to process the IN625-SiC (NiP-coated) particles on it. The laser deposition was done initially by varying the scan speed from 2.5 to $10 \mathrm{~mm} / \mathrm{s}$ in steps of 2.5 at constant laser power of $240 \mathrm{~W}$, beam diameter of $0.4 \mathrm{~mm}$ and hatch spacing of $0.3 \mathrm{~mm}$.

EOSINT M250 Xtended RP machine was used for laser processing of IN625 composites. Laser processing of IN625 composites was tried as per the parameters mentioned in the Table 2. The laser processing was done using $\mathrm{CO}_{2}$ laser of wavelength $10.6 \mu \mathrm{m}$ under inert nitrogen atmosphere to avoid oxidation. The schematic diagram of DMLS process is shown in the Fig. 2. The processed specimens on the substrate were cut using wire electrical discharge machine of make: Charmilles technologies, Switzerland and model: ROBOFIL 290 and deburred for measuring hardness, strength, and for micro-structural analysis. The laser processed specimens were polished for metallographic studies. A mixture of $10 \mathrm{ml} \mathrm{HNO}_{3}, 15 \mathrm{ml} \mathrm{HCl}$ and $10 \mathrm{ml} \mathrm{CH}_{3}-\mathrm{COOH}$ etchant [5] was used for the optical and scanning microscopy. The microstructure investigations were done using optical microscope of make: CLEMEX intelligent microscopy, Canada and model: ST-2000 for optical micrographs and scanning electron microscope of make: Carl Zeiss, and model: Neon 40 crossbeam. The hardness of the processed specimens was conducted using hardness tester of make: CLEMEX DUAL ASPER PO, Canada and model: 07-895 and the indentation was measured using Clemex image analyser software. Hardness was measured at five different locations on the laser processed specimens, using a $300 \mathrm{~g}$ load for a dwell time of 13 seconds. Hardness of each specimen was found by taking average of all the five readings. Tensile test specimens were machined as per the ASTM E8 standard. Tensile behaviour was found by conducting tensile tests at ambient temperature using universal testing machine of make: INSTRON and model: 5569 with data rate of 10 points per sec, load accuracy $\pm 1 \%$, strain rate $0.5 \mathrm{~mm} / \mathrm{min}$.

\section{Results and Discussions}

\section{Particles (Powder) Characterization}

Figure 3 (a) and (b) shows the scanning electron micrograph of IN625 and SiC particles used in this study. It can be seen from the figure that the IN625 particles are spherical in shape and $\mathrm{SiC}$ particles are irregular in shape. The particle size distribution of IN625 is shown in Table 3. The particle size analysis revealed that the size distribution of IN625 varies between $30-60 \mu \mathrm{m}$ and the average size of the $\mathrm{SiC}$ was $28 \mu \mathrm{m}$. The scanning

Table 2 Process parameters for laser processing of IN625-SiC (NiP-coated) composites

\begin{tabular}{ll}
\hline Laser process parameters & Processing values \\
\hline Laser Power (P) (watts) & 240 \\
Laser Scan Speed (V) (mm/s) & $2.5,5.0,7.5,10.0$ \\
Beam Dia. (mm) & 0.4 \\
Hatch Width (mm) & 5 \\
Layer Thickness $(\mathrm{mm})$ & 0.05 \\
Hatch Spacing $(\delta)(\mathrm{mm})$ & 0.3 \\
\hline
\end{tabular}




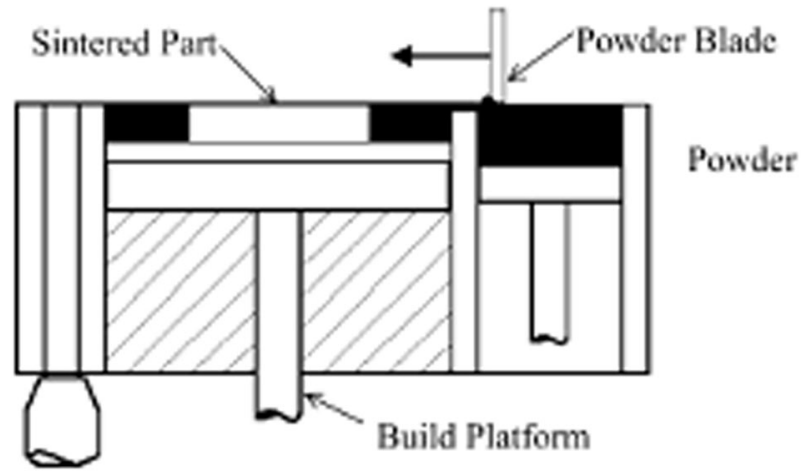

Fig. 2 Schematic diagram of DMLS process

electron micrograph of the $\mathrm{SiC}$ particles shown in Fig. 4 (a) indicate uniform coating of Ni-P and the EDS shown in Fig. 4 (b) indicate the presence of Nickel (Ni) and Phosphorus (P) on the surface of SiC.

\section{Characterization for Mechanical Properties}

IN625-SiC (NiP-coated) composite specimens processed using the parameters mentioned in the Table 2. The specimens with $0.3 \mathrm{~mm}$ hatch spacing were built without any jamming of the re-coater blade almost to the required height of $7 \mathrm{~mm}$ and diameter $12 \mathrm{~mm}$, for all four laser scan speeds for the purpose of evaluating density and hardness.

\section{Density}

The decrease in density of laser processed IN625 and IN625-SiC (NiP-coated) composites can be explained in terms of the laser energy. The energy density of the laser is proportional to the power of laser [4]. The variation in density of composites with laser scan speed is shown in Fig. 5 (a). At lower laser scan speeds, higher heat energy is induced into the particle-bed, leading to an increase in melt temperature. High temperature of the melt leads to less viscosity, higher capillary force and lower contact angle,

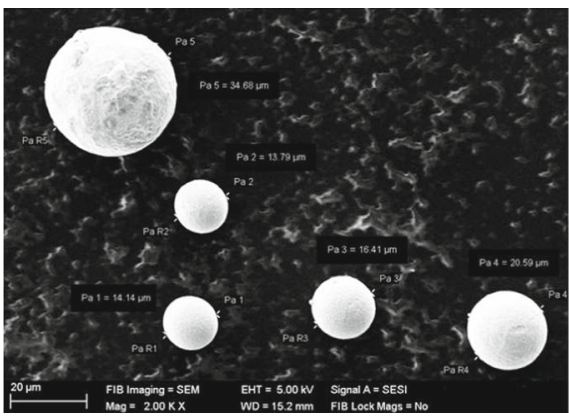

(a) IN625

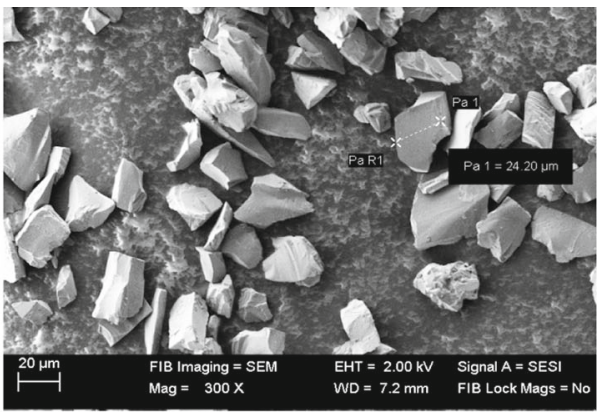

(b) Silicon Carbide

Fig. 3 Scanning electron micrograph 
Table 3 Particle size distribution of IN625

\begin{tabular}{lccccccccc}
\hline Particle size $(\mu \mathrm{m})$ & 10 & 20 & 30 & 40 & 50 & 60 & 70 & 80 & 90 \\
\hline Percentage (\%) & 1.5 & 2.2 & 54.4 & 20.2 & 15.3 & 3.1 & 1.9 & 1.4 & 0 \\
\hline
\end{tabular}

resulting in higher density [18]. At higher laser scan speed, the lower energy density is not good enough to melt all the particles and therefore un-melt particles are left in the laser processed part, which reduces the density. Also the lower energy density induced into the particle-bed, is insufficient for the full melting and therefore the high viscous melt spherodises to form spheres whose diameter is approximately equal to the laser beam diameter. The formation of such spheres (balling) will lead to poor bonding and high porosity in the laser processed part. The resultant effect of balling is poor surface quality, and decrease in density as a consequence of pores [6]. Balling effect in the composites is suppressed by the reinforcements due to higher laser absorption, leading to increase in the melt temperature and thus decreasing its viscosity [13].

The decrease in the density of the composites as shown in Fig. 5 (b) can be attributed to the lower density of NiP-coated SiC reinforcement when compared with IN625 matrix. The density of SiC and IN625 are 3.2 and $8.44 \mathrm{~g} / \mathrm{cc}$ respectively. The population of reinforcement per unit volume increases with addition of more weight percentage of NiP-coated SiC. Therefore, the density of the composites decreases with increase in percentage of the reinforcement [8]. Reduction in density with addition of NiPcoated $\mathrm{SiC}$ weight percentage is significant in case of $5 \mathrm{wt} . \%$ of reinforcement, where a considerable $3.8 \%$ reduction in density with IN625 is observed for a laser scan speed of $2.5 \mathrm{~mm} / \mathrm{s}$.

\section{Hardness}

The improvement in the hardness of the IN625 and IN625-SiC (NiP-coated) composites as shown in Fig. 6 (a) at lower scan speed can be attributed to the increase in density of laser processed parts. Density of the laser processed parts increases with decrease in laser scan speed. As the hardness is because of resistance to plastic deformation, there is an increased resistance to plastic deformation because of increased density, and hence increase in hardness. The higher hardness of SiC and addition of

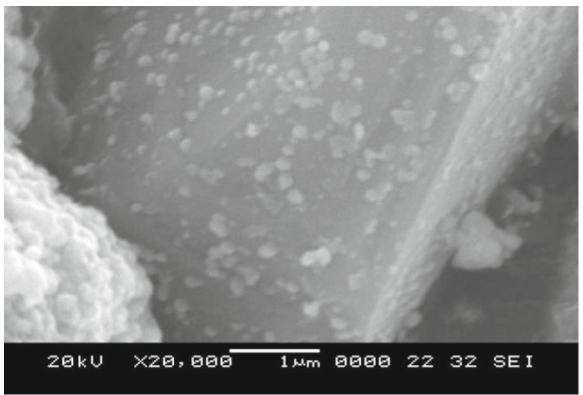

(a)

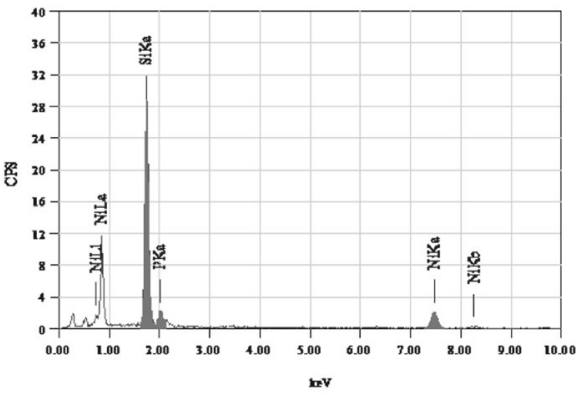

(b)

Fig. 4 SEM and EDS of Ni-P coated SiC particles 


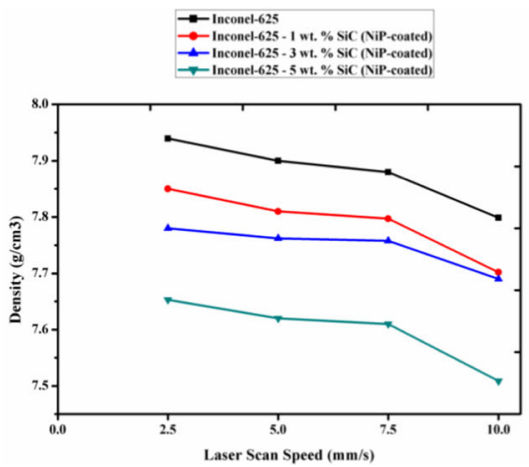

(a) Comparison of Density with Laser Scan Speed

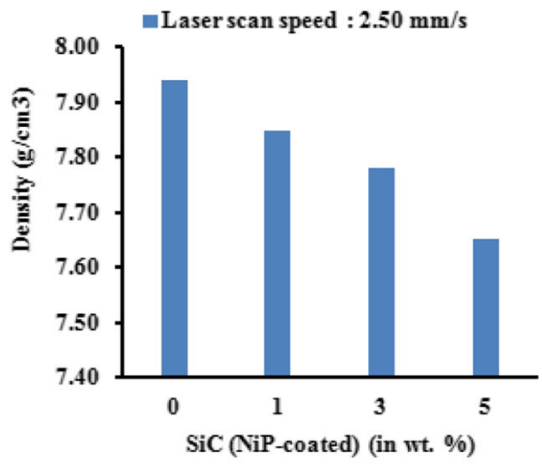

(b) Comparison of Density with Reinforcement

Fig. 5 Effect of laser scan speed and $\mathrm{SiC}$ (NiP-coated) wt. \% on density of IN625 and IN625-SiC (NiP-coated) composites

hard phase into IN625 matrix results in improvement in composite hardness up to 3 weight percentage increase of the reinforcement [16] as shown in Fig. 6 (b).

Figure shows that there is about 13 to $33 \%$ improvement in hardness with the addition of 1 to $3 \mathrm{wt}$. \% reinforcement into the matrix of IN625 for a laser scan speed of $2.5 \mathrm{~mm} / \mathrm{s}$. So, there is a significant improvement in the hardness of the composites by adding different wt. \% of NiP coated $\mathrm{SiC}$ compared to addition of other carbides such as TiC into the matrix of IN625 [3]. One more reason for hardness improvement can be attributed to increased density of dislocation at the matrix-reinforcement interface, which will lead to lowering of mobility of dislocation, which in turn retards the plastic deformation. Higher resistance to plastic deformation results in higher hardness. The increase in the dislocation density can be mainly attributed to the difference in the CTE of IN625 and $\mathrm{SiC}$ [17]. The CTE of IN625 and SiC are 12.8 and 4.8 respectively. Further, the significant improvement in the hardness of the laser processed composites can be attributed to excellent bonding between the reinforcing particle and the matrix as evident from the optical and scanning electron micrographs shown in Figs. 9 and 10.

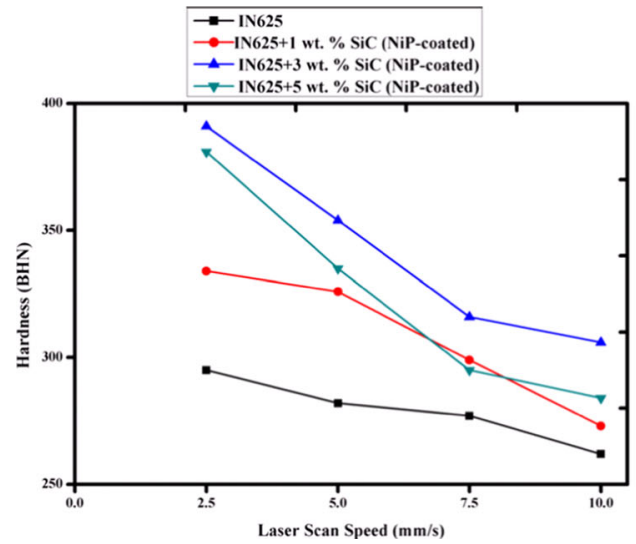

(a) Comparison of Hardness with Laser Scan Speed

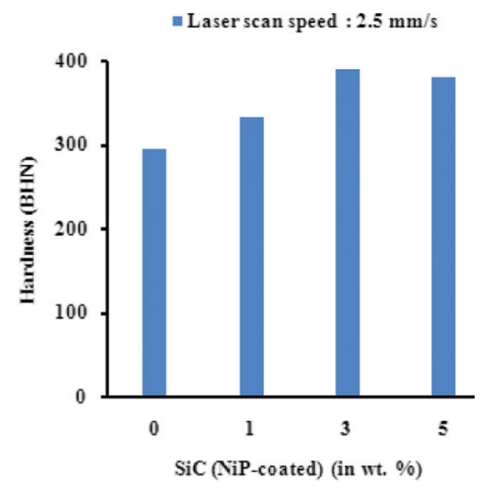

(b) Comparison of Hardness with Reinforcement

Fig. 6 Effect of laser scan speed and SiC (NiP-coated) wt. \% on hardness of IN625 and IN625-SiC (NiP-coated) composites 


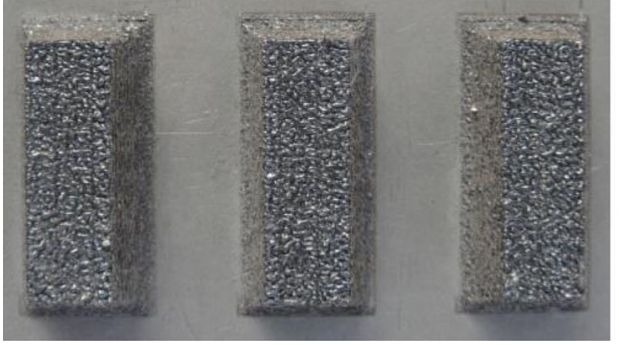

(a) Tensile Specimens before Machining

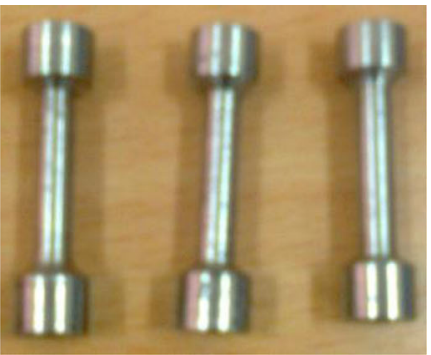

(b) Tensile Specimens after Machining

Fig. 7 Laser processed IN625 composite specimens at $0.3 \mathrm{~mm}$ Hatch Spacing

Thus laser deposition helps in simultaneous building of a material with low density and higher hardness.

\section{Tensile Properties}

Figure 7 (a) and (b) shows the photograph of tensile specimens before and after machining for evaluating ultimate tensile strength (UTS), yield strength (YS) and elongation. The tensile specimens were deposited as shown in the figure by making fillet all round the

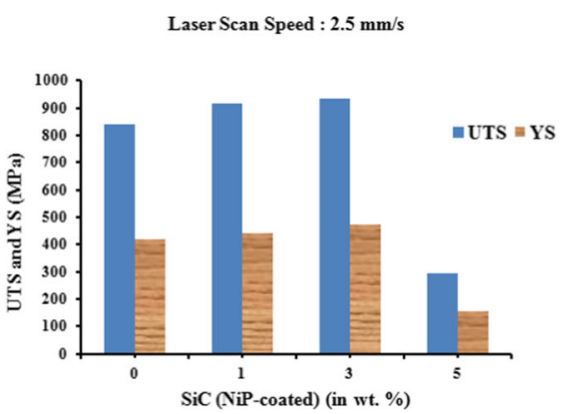

(a) Ultimate Tensile Strength (UTS) \& Yield Strength (YS)

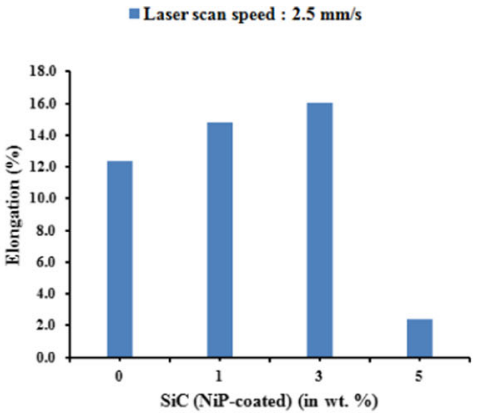

(b) \% Elongation with Variable wt. \% of $\mathrm{SiC}$
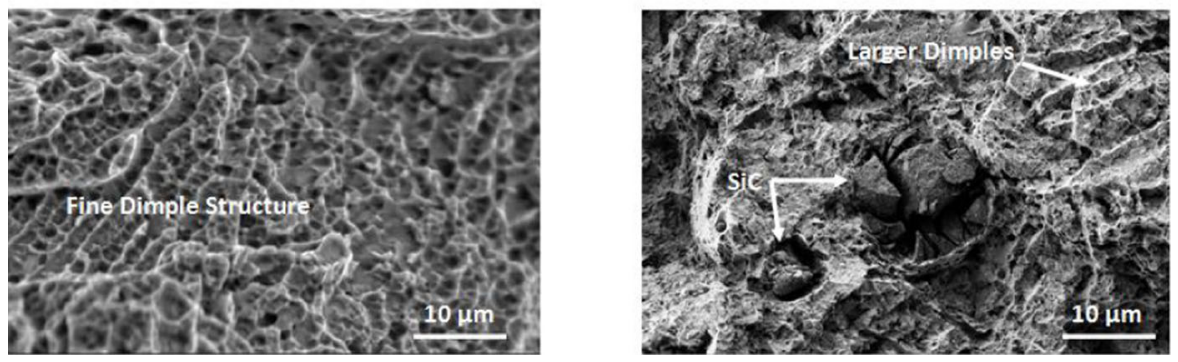

(c) SEM of Fractured Surfaces for IN625 and IN625-5 wt. \% SiC (NiP-coated) Composite

Fig. 8 Effect of SiC (NiP-coated) wt. \% on UTS, YS and \% EL of IN625 and IN625-SiC (NiP-coated) composites 
bottom side of the specimen for the purpose of thermal gradient and to avoid warpage of build parts during laser deposition. The out puts of the tensile test of the laser deposited IN625, IN625-1 wt. \% SiC (NiP-coated), IN625-3 wt. \% SiC (NiP-coated), IN625-5 wt. \% SiC (NiP-coated) MMCs are summarised in the Fig. 8 (a) and (b). The laser deposited IN625 MMCs shows a significant improvement in the UTS, YS and reduction in elongation compared to laser deposited IN625 for a laser scan speed of $2.5 \mathrm{~mm} / \mathrm{s}$. With the addition of $3 \mathrm{wt}$ \% of reinforcement, the UTS and YS increases by 12 and $10 \%$ respectively, compared to laser deposition of IN625. The increasing trend is observed for UTS, and YS with increase in addition of reinforcement into IN625 matrix upto $3 \mathrm{wt}$. \% and further addition of reinforcement has resulted in drastic reduction in UTS, and YS. The addition of reinforcement results in absorption of larger part of the incident laser beam; this in turn improves the solidification with creation of more grain boundaries. More grain boundaries mean more opposition to dislocation which finally results in strengthening of the material. The refractory effect of reinforcement particles also results increased dislocation density. Better flowability and improvement of interfacial behaviour between reinforcement and the matrix because of NiP coating on $\mathrm{SiC}$ also results in increased strength and reduction of porosity.

The fracture surface of the IN625 shown in Fig. 8(c) exhibits a fine dimpled surface, which is the characteristic of dimpled ductile mode of failure with good tensile properties, whereas IN625 with 5 wt. \% SiC (NiP-coated) reinforcement shows dimples of larger size, which is the characteristic of brittle mode of failure with poor tensile properties
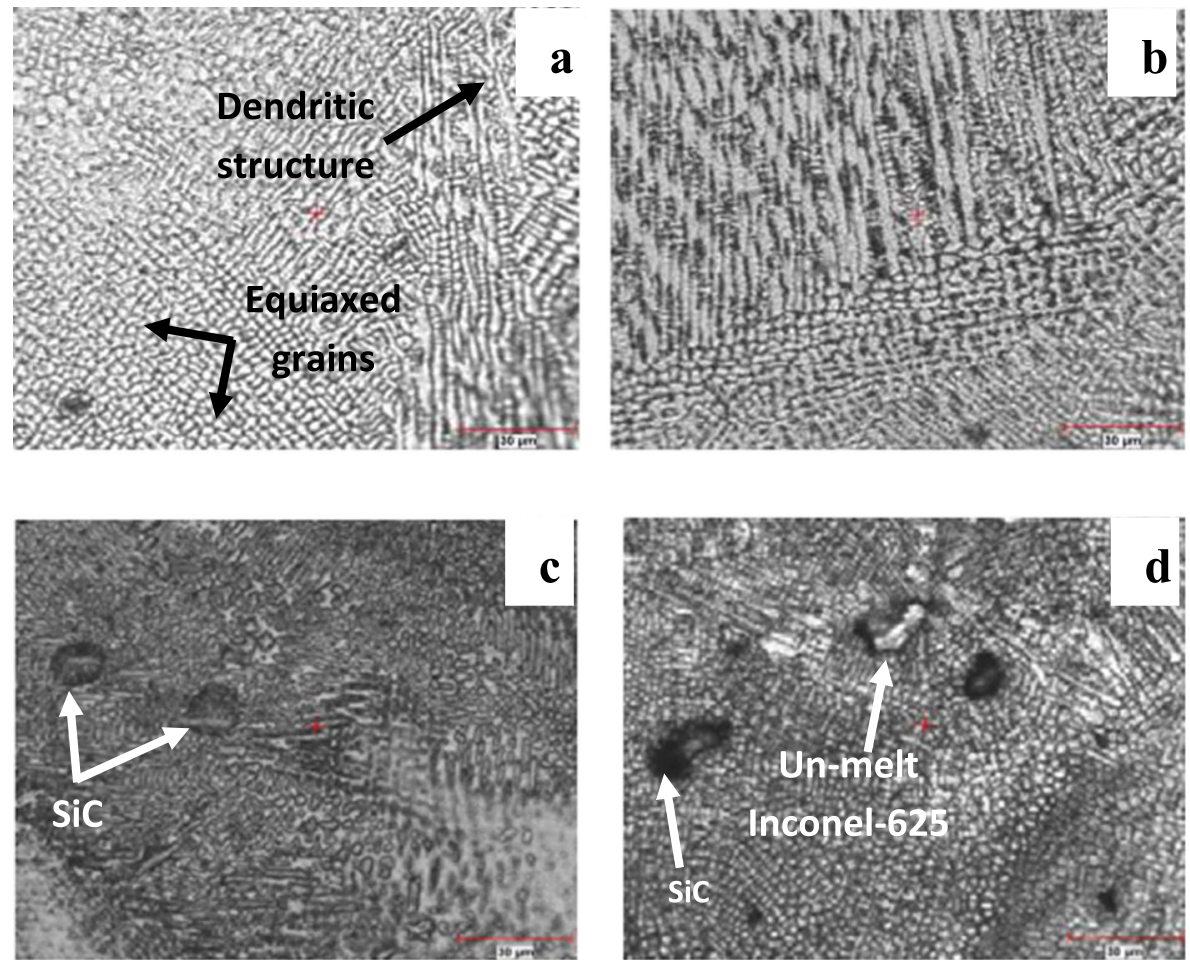

Fig. 9 Optical micrographs of IN625 (a) \& (b) and IN625-5 wt. \% SiC (NiP-coated) (c) \& (d) at a laser scan speeds of 2.5 and $10 \mathrm{~mm} / \mathrm{s}$ respectively 


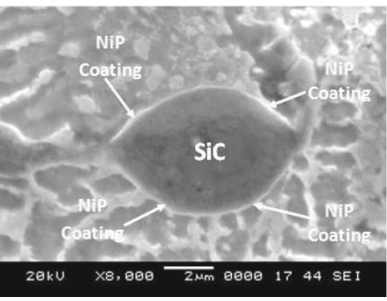

(a) SiC Particle Encapsulated with Ni-P Coating

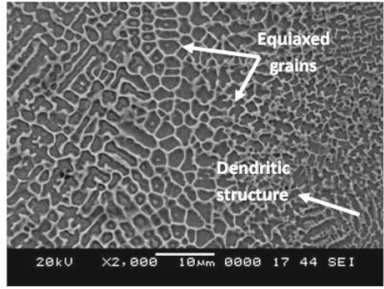

(b) IN625

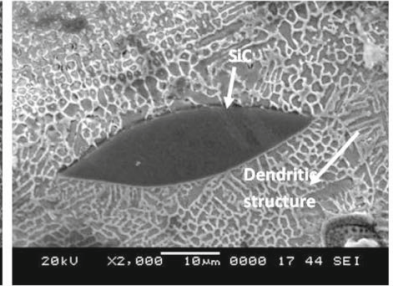

(c) IN625-5 wt. \% SiC (NiP-Coated)

Fig. 10 Scanning electron micrographs of IN625-SiC (NiP-coated) composites

because of increased weight percentage of reinforcement particles. The drastic reduction in UTS, YS and elongation with the increase in reinforcement wt. \% beyond 3 can be attributed to increase in thermal cracking with increase in weight percentage of Ni-P coated $\mathrm{SiC}$ reinforcement particles. The brittleness induced because of higher weight percentage of hard coated ceramic reinforcement results in higher cracking within the material, indicating lower yield strength and ductility. Thermo-elastic mismatch between IN625 matrix and SiC reinforcement leads to a large stress concentration near the Ni-P coated $\mathrm{SiC}$ reinforcement leading to premature failure during straining, indicating lower UTS. This inference is in agreement with other researchers also [17].

\section{Microstructure Analysis}

The scanning electron micrograph shown in Fig. 10 (a) indicates the complete encapsulation of the irregular $\mathrm{SiC}$ particles by Ni-P coating with a thickness of 1 to $2 \mu \mathrm{m}$. The morphology of coated SiC particles is smooth and more spherical when compared to the uncoated $\mathrm{SiC}$ particles. The evidence shown by the scanning electron micrograph for the presence of $\mathrm{SiC}$ particles supports the suggestion of a perfect bonding between $\mathrm{SiC}$ particles and Ni-P coating. Figures 9 and 10 shows the optical and scanning electron micrographs of laser processed pure IN625 and IN625 composites for different laser scan speeds of 2.5 and $10 \mathrm{~mm} / \mathrm{s}$. Figure 11 shows the distribution of $\mathrm{SiC}$ particles in IN625 matrix at lower magnification. The microstructure examination clearly reveals the presence of both cellular and dendritic form of microstructure. The ductility is kept intact because of the presence of cellular microstructure [11]. The cellular and dendritic

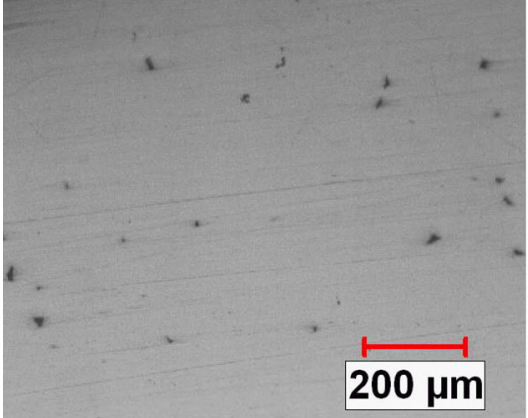

(a) For Laser Scan Speed of $2.5 \mathrm{~mm} / \mathrm{s}$

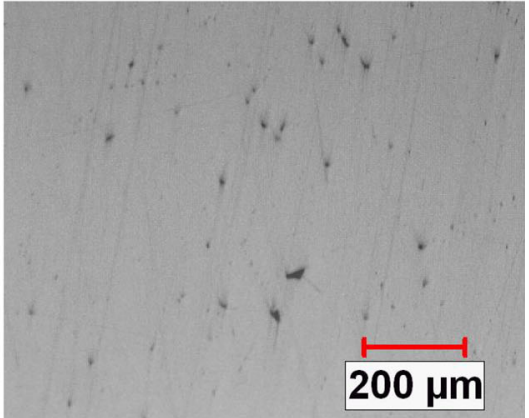

(b) For Laser Scan Speed of $10 \mathrm{~mm} / \mathrm{s}$

Fig. 11 Optical micrographs at magnification of $100 \mathrm{X}$ 
microstructures are attributed to reduced cooling rate and rapid cooling rates respectively. The high hardness is because of the presence of fine microstructures with high dislocation density. The rapid cooling rate and an increased dislocation density during laser processing results in grain refinement of IN625 matrix.The large amount of dislocations is the result of residual stress between the matrix and reinforcement, generated due to rapid cooling and heating because of difference in CTE between the $\mathrm{SiC}$ reinforcement and the IN625 matrix. The additive nature results in lot of changes in the thermal behaviour of the process. The thermal stress developed during the process because of multiple reheating cycles also results in generation of high dislocations in IN625 matrix. The perfect interface between the reinforcement and the matrix without any voids, cracks shows the dispersion of reinforcement particles in the IN625 matrix.

Lower scan speed results in higher laser power density and higher laser power density results in cellular microstructure with dendrites. The movement of dislocations is hindered due to the presence of dendritic phase. The hardness is increased due to dendritic phase and the secondary $\mathrm{SiC}$, which acts as dispersoid and hinders the movement of dislocations [1]. The dendrites grow along the direction of deposition.

Increase in wt. percentage of reinforcement results in more absorption of laser energy, more laser energy absorption leads to fine microstructure with dendrites, which again results in increased hardness because of $\mathrm{C}$ and $\mathrm{Si}$ atom introduction into the lattice of IN625. This is in agreement with other researchers also [2].

Thus the micrographs clearly indicate that the laser scan speed and the reinforcement have significant effect on microstructure of the laser processed parts.

\section{Conclusions}

Deposition of IN625 with addition of variable wt. \% of NiP coated SiC particles using laser additive manufacturing process was investigated. The microstructure, density, hardness and tensile properties of the deposited material and composites were studied. The following conclusions are drawn from the present studies on IN625 and IN625 composites:

- Coated SiC particles with NiP can be used to reinforce IN625 using laser additive DMLS process.

- The microstructure of IN625 matrix become more refined with the addition of more reinforcement particles, and laser scan speed, and the grain shape shifted from columnar dendrite to cellular equiaxed form.

- Increase in hardness by $33 \%$ over the base IN625 material because of refinement in microstructure with more addition of reinforcement.

- Significant improvement in tensile properties due to microstructure refinement and strengthening effect by addition of NiP encapsulated SiC particle.

- Lower density and hardness, at higher scan speed due to increased porosity. 


\section{References}

1. Ahmad, M., Akhter, J.I., Iqbal, M., Akhtar, M., Ahmed, E., Shaikh, A., Saeed, K.: Surface modification of Hastelloy C-276 by SiC addition and electron beam melting. J Nucl Mater 336, 120-124 (2005)

2. Ahmad, M., Ali, G., Ahmed, E., Haq, H.A., Akhter, J.I.: Novel microstructural growth in the surface of Inconel 625 by the addition of SiC under electron beam melting. Appl Surf Sci 257, 7405-7410 (2011)

3. Bi, G., Sun, C.N., Nai, M.L., Wei, J.: Micro-structure and mechanical properties of nano-TiC reinforced Inconel 625 deposited using LAAM. Phys Procedia 41, 828-834 (2013)

4. Calignano, F., Manfredi, D., Ambrosio, E.P., Iuliano, L., Fino, P.: Influence of process parameters on surface roughness of aluminium parts produced by DMLS. Int J Adv Manuf Technol 67, 2743-2751 (2013)

5. Dinda, G.P., Dasgupta, A.K., Mazumder, J.: Laser aided direct metal deposition of Inconel 625 superalloy: Microstructural evolution and thermal stability. Mater Sci Eng A 509(1-2), 98-104 (2009)

6. Gu, D., Shen: Balling phenomena in direct laser sintering of SS powder: Metallurgical mechanisms and control methods. Mater Des 30(8), 2903-2910 (2009)

7. Kang, M., Man, J., Kimb, Kima, J.W., Kimc, Y.K., Chungd, H., Yiea, J.E.: Simple and fast microwaveenhanced wet etching of SiC particles for electroless Ni-P plating. J Surf Coat Technol 161, 79-85 (2002)

8. Li, X.C., Prinz, F.: Mechanical and thermal expansion behavior of laser deposited metal matrix composites of Invar and TiC. Mater Sci Eng A 282, 86-90 (2000)

9. Liu, G.W., Muolo, M.L., Valenza, F., Passerone, A.: Survey on wetting of SiC by molten metals. Ceramics International 36(4), 1177-1188 (2010)

10. Miracle, D.B.: Metal matrix composites-From science to technological significance. Compos Sci Technol 65, 2526-2540 (2005)

11. Paul, C.P., Ganesh, P., Mishra, S.K., Bhargava, P., Negi, J., Nath, A.K.: Investigating laser rapid manufacturing for Inconel-625 components. Opt Laser Technol 39(4), 800-805 (2007)

12. Salman, P., Amir, R., Ibrahim, D., Mihal, N.: Influence of tool materials on machinability of titanium and nickel-based alloys: A review. Mater Manuf Process 29, 219-252 (2014)

13. Simchi, A., Godlinski: Effect of SiC particles on the laser sintering Al-7Si-0.3 Mg alloy. Scr Mater 59, 199-202 (2008)

14. Srinivasa, C.K.: Blending of iron and silicon carbide powders for producing metal matrix composites by laser sintering process. J Rapid prototyp 16(4), 258-267 (2010)

15. Shankar, V., Rao, K.B.S., Mannan, S.L.: Microstructure and mechanical properties of Inconel 625 superalloy. J Nucl Mater 288, 222-232 (2001)

16. Wilson, M.J., Shin, Y.C.: Microstructure and wear properties of laser deposited functionally graded Inconel 690 reinforced with TiC. Suraf Coat Technol 207, 517-522 (2012)

17. Zheng, B., Topping, T., Smugeresky, J.E., Zhou, Y., Biswas, A., Baker, D., Lavernia, E.J.: The influence of Ni-coated TiC on laser-deposited Inconel-625 metal matrix composites. Metall Mater Trans A 41A, 568-573 (2010)

18. Zhu, H.H.: Microstructural evolution in direct laser sintering of Cu-based metal powder. J Rapid Prototyp 11(2), 74-61 (2005)

19. Zhu, S.M., Wang, L., Li, G.B., Tjong, S.C.: Laser surface alloying of Incoloy $800 \mathrm{H}$ with silicon carbide: microstructural aspects. Mater Sci Eng A 201, L5-L7 (1995) 